Nuntius Antiquus, Belo Horizonte, v. 12, n. 2, p. 7-25, 2016

\title{
Declamação e Comédia Nova: estereótipos cômicos de velho avarento em exercícios retóricos gregos
}

\author{
Declamation and New Comedy: comic stereotypes \\ of miser old men in Greek rhetorical exercises
}

Barbara da Costa e Silva
Universidade de São Paulo
São Paulo, São Paulo / Brasil
barbaradacostaesilva@gmail.com

Resumo: Neste artigo, pretendo realçar alguns pontos de conexão entre a caracterização do velho avarento em duas declamações gregas de Libânio e de Corício e o modo como tal personagem é representada nas Comédias Novas, especialmente nas de Menandro. As semelhanças são abundantes e patentes. Há suficiente evidência para provar que Menandro foi um autor lido e emulado em círculos de estudo da oratória: inúmeros testimonia antigos, como Quintiliano e Dião Crisóstomo, confirmam tal afirmação. Nessa medida, este artigo investiga as razões que motivaram a alusão deliberada a Menandro nas declamações mencionadas.

Palavras-chave: retórica; Comédia Nova; declamação; Libânio; Corício.

Abstract: In this paper I intend to highlight a few points of connection between the characterization of the miser old men in New Comedy and in Greek declamations, which are Libanius' and Choricius'. The similarities are vast and easily recognizable. There is enough evidence to confirm that Menander was an author whose work was read and imitated in the schools of rhetoric: many testimonia, like Quintilian and Dio Chrysostomus, confirm this assertion. Therefore, this paper investigates the reasons which compelled declaimers to alude to Menander in such a deliberatively way.

Keywords: rhetoric; New Comedy; declamation; Libanius; Choricius. 
Recebido em 17 de outubro de 2016. Aprovado em 23 de dezembro de 2016.

Por "declamação", entende-se o discurso que imita um discurso judiciário ou deliberativo e é baseado em personagens e enredos mitológico-literários, históricos ou etológicos, i.e. enredos nos quais as personagens são tipos. ${ }^{1}$ Os primeiros expoentes do gênero são os discursosmodelares dos quais os sofistas, ainda no século V a.C., se valiam em suas lições de oratória, como é o caso das orações creditadas a Górgias. A prática, apesar de ter sido originada ainda no séc. IV a.C., adquiriu uma imensa popularidade em períodos posteriores, particularmente no período imperial, do qual provém a grande maioria dos textos declamatórios supérstites. O corpus que restou de declamações, tanto gregas quanto latinas, é enorme, mas ainda pouco estudado e traduzido. As latinas, que nos últimos anos se tornaram objeto de inúmeros estudos críticos, são datadas entre os primeiros anos do Império até, aproximadamente, o séc. II d.C. ${ }^{2}$ As declamações em grego, por sua vez, são datadas dos sécs. I-II d.C. até o séc. VI d.C., e para a maior porção delas não há traduções. ${ }^{3}$

Dentre o corpus grego, inquestionavelmente se destacam as declamações de Libânio, mestre de retórica que viveu no século IV d.C. e sobre o qual somos bem informados devido à extensão de sua obra epistolar, e as de Corício, um professor que viveu e trabalhou na Gaza do século VI. A Libânio, são creditadas cinquenta e uma declamações, que estão em bom estado de preservação e são discursos inteiros e não fragmentos de discurso. Sob o nome de Corício, restaram doze

\footnotetext{
1 "Etológico" é um termo técnico largamente utilizado hodiernamente por especialistas em declamação. Já Richsteig nos Prolegomena de sua edição Teubner da obra de Corício (Leipzig, 1929) propõe tal distinção.

${ }^{2}$ Algumas referências à declamação podem já ser encontradas na obra de Cícero, mas é somente no Império, com o livro de Sêneca, Controvérsias e Suasórias, que se encontra o primeiro testemunho mais completo da prática. Declamações também são creditadas a Quintiliano, hoje consideradas espúrias, e a Calpúrnio Flaco. As Declamações Maiores de Pseudo-Quintiliano parecem ser as mais tardias, possivelmente do século II d.C.

${ }^{3}$ Para as declamações gregas, o estudo mais informativo ainda é o de Russell (1983). Sobre as declamações latinas, o livro base é o de Bonner (1949). Tanto um quanto o outro merecem ser lidos com cautela, mas fornecem bons panoramas sobre o gênero.
} 
declamações preservadas integralmente, à exceção de algumas poucas lacunas textuais.

A declamação, além de ser o principal instrumento pedagógico à disposição do professor de retórica, era também um gênero extraliterário, um passatempo cujo fim era o deleite, praticado por homens alheios ao dia a dia da escola. As evidências que atestam essa dupla função do gênero declamatório datam desde, pelo menos, o século I d.C., mas já em Cícero vê-se a presença de exercícios retóricos praticados fora da privacidade da escola ou das casas. Esse caráter ambivalente fez com que inúmeros estudiosos modernos propusessem nomenclaturas que distinguem os tipos de declamação: scholastic declamation vs. show declamation, Schuldeklamation vs. Schaudeklamation são apenas alguns exemplos. ${ }^{4}$ Com efeito, as duas funções da declamação não deveriam ser delimitadas de forma tão rígida na Antiguidade. Sabe-se de professores de retórica e de sofistas que tanto declamavam publicamente, em reuniões abertas, quanto ensinavam a oratória a partir da declamação. ${ }^{5}$ Libânio e Corício parecem se encaixar nessa categoria de declamador-professor: ambos utilizavam declamações em suas aulas, mas também há informação de que ambos declamavam em festivais públicos. De fato, a relação entre as duas formas declamatórias é simbiótica: o professor adquiria renome declamando publicamente, e quanto maior fosse sua fama, maior seria também seu número de alunos. ${ }^{6}$

Um aspecto bastante valorizado em textos antigos voltados à declamação, tanto à escolar quanto à epidítica, é a performance persuasiva

\footnotetext{
${ }^{4}$ A divisão bem demarcada entre declamação escolar e não escolar é bastante presente nos escritos de alguns autores como Hömke (2007; 2009). Stramaglia (2015, p. 27, nota 1) traz um breve panorama do estado da pesquisa quanto à questão. Para os alemães, segundo Stramaglia, parece haver até mesmo uma divisão tripla: Schuldeklamation (declamação escolar), Hobbydeklamation (declamação que visa ao lazer, mas também à instrução) e Schaudeklamation (apenas para lazer). Quintiliano dá testemunho apenas acerca da divisão canônica em declamação escolar e para o entretenimento (in ostentationem). Cf. Quintiliano, 2.10.7-12.

${ }^{5}$ Filóstrato, Vidas dos Sofistas, 528, 537, 601.

${ }^{6}$ Cf. Russell (1983, p. 74); Kennedy (1974, passim).
} 
e ardente. ${ }^{7} \mathrm{O}$ declamador era, antes de tudo, um ator. ${ }^{8}$ Pedia-se que o orador representasse personagens e situações previamente selecionadas de modo a se adequar ao caráter da persona, o que confere à declamação uma dinâmica teatral; há, inclusive, testemunhos de declamadores que utilizavam cenários e figurino em suas apresentações. ${ }^{9}$

Nesta configuração, Menandro surge como uma das vozes que perpetuam valores estimados entre os declamadores, especialmente os relacionados à imitação convincente e à pluralidade de caracteres imitados. O célebre epigrama creditado a Aristófanes de Bizâncio, no qual o realismo dos dramas é sublinhado, sobreviveu justamente em um comentário a um tratado sobre a teoria dos estados da causa, um dos métodos utilizados pelos antigos para ensinar a declamar. A passagem em questão está em "Comentários ao Livro sobre os estados de causa de

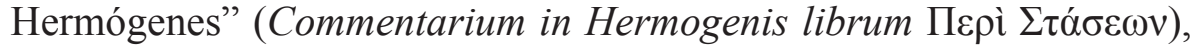
obra creditada ao neoplatônico Siriano (séc. V d.C.):

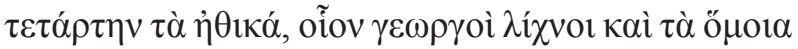

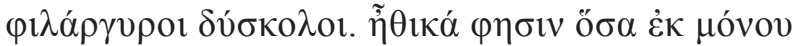

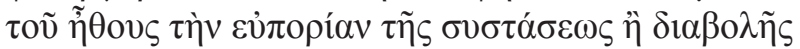

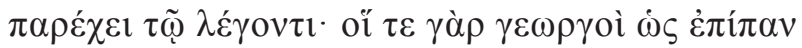

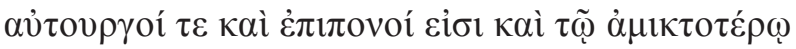

${ }^{7}$ Em Sêneca, Controvérsias e Suasórias (Contr. 3. Praef. §7), louvam-se como qualidades do bonus declamator a "dicção não vulgar, nem baixa, mas seleta" (phrasin non uulgarem nec sordidam sed electam), um "tipo de oratória não relaxada e nem lânguida, mas ardente e arrebatada" (genus dicendi non remissum aut languidum sed ardens et concitatum), uma explanação "nem lenta e nem vazia, mas tendo mais sentido do que palavras" (non lentas nec uacuas explicationes, sed plus sensuum quam uerborum habentes) e "diligência" (diligentiam). Similarmente, Filóstrato (VS 569) elenca as características que faziam de Antíoco um bom declamador: "impetuosidade nas

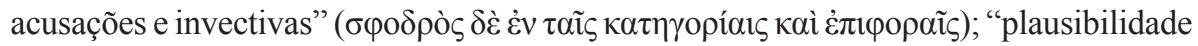

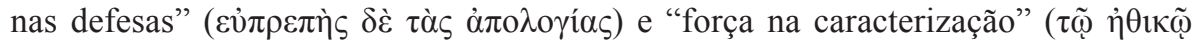

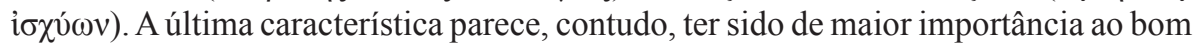
declamador. Luciano em Sobre a dança (Salt. §65) afirma que, assim como o ator, aquele que compõe declamações deve adequar a linguagem ao caráter do imitado: um príncipe, um tiranicida, um rico, um pobre.

${ }^{8}$ A aproximação entre o orador e o ator, quando se fala de declamação, encontra seu ápice na dialéxis 12 (XXI F.-R.) de Corício, na qual o declamador busca aproximar suas atividades às do dançarino de pantomima.

${ }^{9}$ Filóstrato, Vidas 537. 


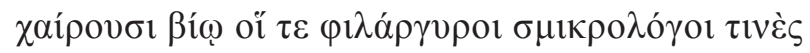

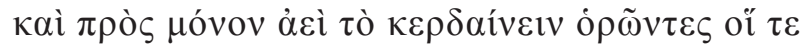

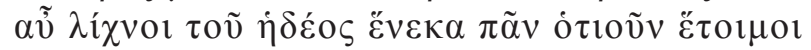

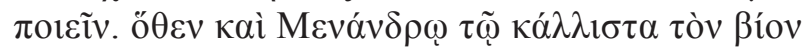

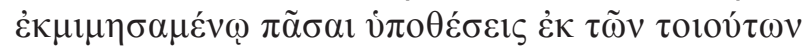

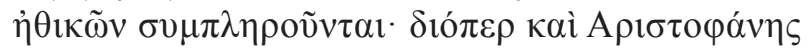

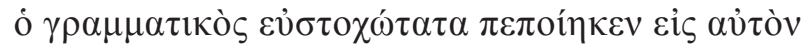

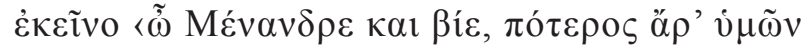

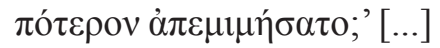

Em quarto lugar estão as [personagens] éticas, como fazendeiros, glutões, avarentos, misantropos, etc. Ele [Hermógenes] chama de éticas aquelas que fornecem, a partir de um único traço de caráter, material para um aconselhamento ou para uma acusação. Os fazendeiros são sempre autônomos e trabalhadores e se sentem felizes por terem um estilo de vida mais simples. Já alguns avarentos são muquiranas e visam somente ao lucro. Os glutões estão dispostos a fazer qualquer coisa pelo prazer. Deste modo, os enredos todos são preenchidos também por Menandro, que belamente imitou a vida. Por isso, Aristófanes, o gramático, teceu afirmações acertadas sobre ele [Menandro]:

Menandro e Vida,

Quem de vós imitou quem? [... $]^{10}$

Os traços realistas dos dramas e a diversidade das personagens representadas fizeram que Menandro fosse, já bem antes do século V de Siriano, um autor cuja leitura era recomendada aos oradores em formação. Tanto Dioniso de Halicarnasso em Sobre a imitação (2.11) quanto Dião Crisóstomo em Sobre o treinamento em oratória (Or. 18, 6-7) reconhecem

${ }^{10}$ Siriano, Comentário 2. 23 Rabe (Men T 32 K-T). As traduções gregas e latinas citadas são minhas, exceto quando indicadas. A edição utilizada para os testemunhos e fragmentos menandrianos é a de Körte-Thierfelder (Teubner, 1959), doravante K-T. Todos os outros textos gregos e latinos citados tiveram suas edições consultadas a partir do Thesaurus Linguae Graecae (TLG) e Thesaurus Linguae Latinae (TLL), salvo quando indicado. 
a capacidade imitativa do comediógrafo, aconselhando sua leitura aos jovens interessados em oratória. Dião, por exemplo, prefere Menandro a Aristófanes e Eurípides a Ésquilo e justifica:

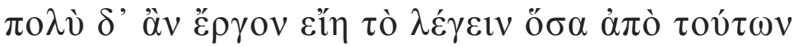

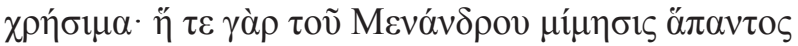

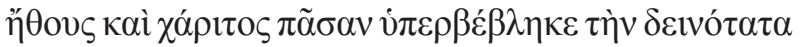

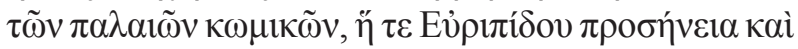

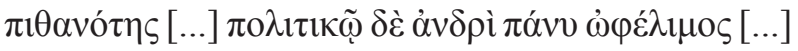

Seria um trabalho muito árduo enumerar as qualidades deles [de Menandro e de Eurípides]. A imitação de Menandro de todos os caracteres e de todo charme superou as melhores habilidades dos comediógrafos antigos, e a suavidade e a capacidade persuasiva de Eurípides $[\ldots]$ são úteis ao homem político. ${ }^{11}$

Quintiliano, em 10.1.69, de modo semelhante, recomenda a leitura arguta de Menandro ao orador. Ele, porém, é ainda mais específico ao destacar a utilidade do estudo das peças menandrianas sobretudo aos declamadores. Em 10.1.71, a opinião de Quintiliano é a de que Menandro, além de ser útil a qualquer orador, é especialmente proveitoso ao declamador (ego tamen plus adhuc quiddam conlaturum eum declamatoribus puto - "quanto a mim, penso que ele tem ainda mais a acrescentar aos declamadores"), cuja tarefa é representar inúmeras personae (pais, filhos, solteirões, maridos, soldados, fazendeiros, ricos, pobres, irados, submissos, etc.) segundo as condições da controvérsia proposta.

Não somente ao declamador - ou melhor, ao estudante avançado da oratória - os testemunhos antigos recomendam o estudo das peças de Menandro. Autores antigos, como Sexto Empírico (Contra os matemáticos, I. 58), preconizavam tal estudo aos alunos do gramático. $\mathrm{O}$ estabelecimento de Menandro como um autor importante à formação do jovem se deu poucas décadas após a morte do comediógrafo. Já no séc. II a.C., é possível identificar versos extraídos de Menandro em antologias de máximas, as $\gamma \nu \tilde{\omega} \mu \alpha$, cujo uso restringia-se às fases mais elementares da alfabetização do jovem. ${ }^{12}$

\footnotetext{
${ }^{11}$ Dião Crisóstomo, Or. 18, 7 (Men T 40 K-T).

${ }^{12}$ Cf. Nervegna (2013, p. 201-251).
} 
Com efeito, os testemunhos indicam que material menandriano circulava nas escolas desde os estágios mais básicos da educação do jovem. O contato do estudante com Menandro se dava seja pelas antologias de máximas, copiadas e memorizadas como método de alfabetização, ou pelos excertos de peças, cujo objetivo era fornecer um modelo, como é o caso dos discursos forenses em Epitrépontes, citados por Quintiliano como modelos do gênero, ${ }^{13}$ ou pelos dramas completos, como atesta Corício, que, em Decl. 12 th. $\S \S 1-2$, diz que inseriu em sua declamação um militar insolente justamente por ter como modelo Trasonides na peça menandriana Misoúmenos. ${ }^{14}$

De fato, os pontos de sutura entre a representação de algumas personagens declamatórias e as menandrianas são tão patentes que, em uma época anterior à publicação da primeira peça integral, Díscolo, que ocorreu em 1958-9, os críticos voltavam-se às declamações tardias na tentativa de reconstrução dos enredos dramáticos das peças do comediógrafo. Um estudo que ilustra bem tal empreitada é o de Pack (1935), que buscava reconstruir as características principais da personagem Cnémon a partir do velho avarento da Decl. 6 de Corício.

\section{Estudo de caso: o velho avarento nas declamações gregas}

Realmente há inúmeros pontos de intersecção entre as personagens menandrianas e as declamatórias. Tendo em vista o objetivo deste artigo, atenho-me somente à personagem do velho avarento em Menandro e nas declamações de Libânio e de Corício.

$\mathrm{O}$ velho avarento, em Menandro, com frequência é referido pelo nome artificial "Esmícrines", uma forma possivelmente cognata de $\sigma \mu 1 \kappa \rho o ́ \varsigma$ ("pequeno"), que denota uma associação entre o nome da personagem e seu caráter avarento, uma vez que o avarento é descrito em termos de $\mu 1 \kappa p o \lambda$ oría (um composto do adjetivo "pequeno") nos Caracteres de Teofrasto. ${ }^{15}$ Nas declamações etológicas, nomes não são

\footnotetext{
${ }^{13}$ Quintiliano, 10.1.70; Anônimo Segueriano, §§33-4.

${ }^{14}$ Em Or. 32, §73, Corício menciona quatro personagens de Menandro, indicando que talvez conhecesse de modo integral pelo menos as peças Díscolo, Epitrépontes e Sámia. ${ }_{15}$ MacCary (1970, p. 282); Teofrasto, Characteres X. Além de $\mu 1 \kappa \rho o \lambda o \gamma i ́ \alpha$ ("mesquinharia"), Teofrasto também descreve o avarento através de $\alpha i \sigma \chi \rho о \kappa \varepsilon ́ \rho \delta \varepsilon 1 \alpha$

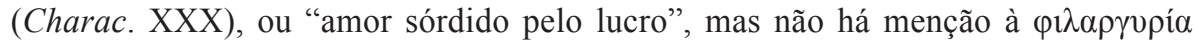
("amor pelo dinheiro"), que é o elemento mais distintivo da personagem do avarento nas
} 
utilizados, de forma que o sovina é descrito apenas como $\varphi \imath \lambda \alpha ́ \rho \gamma v \rho \circ \varsigma$ ("amante do dinheiro"). Corício, em Or. 32,§73 F.-R., menciona a personagem menandriana Esmícrines qualificando-a como um

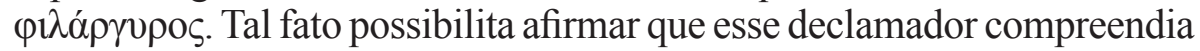

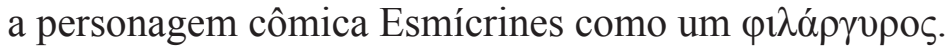

$\mathrm{O}$ velho avarento é apenas uma subdivisão de personagens caracterizadas pela idade avançada nas comédias. ${ }^{16} \mathrm{O}$ traço ético mais saliente é a frugalidade - ocasionada por diversas razões (pretensa pobreza ou misantropia, por exemplo) - que os faz se contorcerem à ideia de perder qualquer tostão que seja - nas declamações, perder dinheiro chega a ser um pretexto para a morte. Em Chor. Decl. 6, por exemplo, o sovina se coloca contra o casamento de seu filho com uma noiva sem dote. Em Lib. Decl. 33, o velho deserda seu filho herói por ter pedido como prêmio pelo heroísmo uma simples coroa de louros e não ouro. Em Lib. Decl. 31, um avarento que tem uma dívida de mil dracmas com a cidade vai à assembleia buscar o direito de se suicidar. Em Lib. Decl. 32, o velho avarento, apaixonado por uma cortesã, se recusa a pagar o imposto exigido e denuncia-se ao tribunal. ${ }^{17}$

Com efeito, inúmeros traços éticos trabalhados nas declamações encontram respaldo em velhos cômicos. Por exemplo, na sexta declamação de Corício o velho começa a narração expondo sua contumaz mesquinhez:

declamações, bem como é uma característica central dos velhos Esmícrines em Áspis e Epitrépontes.

${ }^{16}$ Sobre a caracterização dessa personagem em Menandro, cf. MacCary (1970; 1971). Segundo o estudioso, o comediógrafo da Comédia Nova molda suas personagens segundo um quadro determinado de características, tanto externas (figurino, máscara e equipamentos) quanto psicológicas (padrões comportamentais, uso da linguagem, etc.), que, de imediato, informariam aos espectadores qual seria o tipo de personagem (um escravo, um homem livre, etc.). Contudo, a caracterização dos indivíduos pode ser complexa. Por vezes, Menandro mescla características de dois tipos em uma personagem - o exemplo clássico é o soldado apaixonado em Perikeiroméne e Misoúmenos - de modo a jogar com as expectativas da audiência. Desse modo, a caracterização das personagens em Menandro torna-se um problema em si, do qual não tratarei no presente trabalho.

${ }^{17}$ As declamações 31 e 32 de Libânio são discursos figurados; a verdadeira intenção dos velhos não é a morte, mas sim o perdão das dívidas, como nota Russell (1996: 135). 


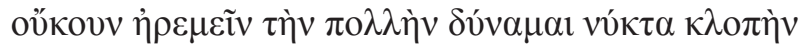

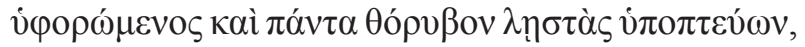

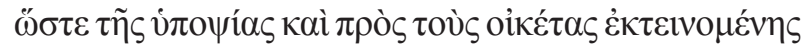

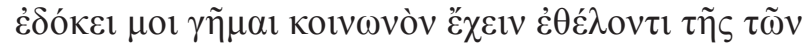

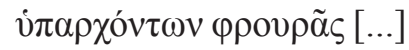

Não consigo relaxar durante a noite com tantos furtos, vigio e suspeito de qualquer barulho de ladrões; a suspeita estendia-se também aos criados. Pareceume uma boa ideia casar, pois desejava compartilhar a vigília dos bens $[\ldots]^{18}$

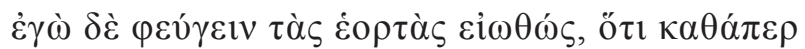

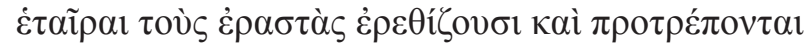
$\delta \alpha \pi \alpha v \tilde{\alpha} v[\ldots]$

Eu me acostumei a evitar as festividades, pois assim como as cortesãs provocam os amantes, os festivais provocam gastos. ${ }^{19}$

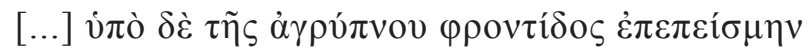

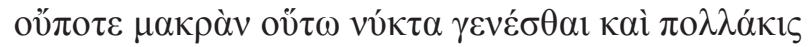

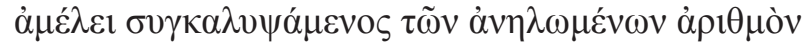
$\dot{\varepsilon} \pi 010 v ́ \mu \eta \nu[\ldots]$

Caí, então, sobre meus pensamentos insones com a certeza de que jamais houvera noite tão longa e repetidamente calculei o montante dos gastos embaixo das cobertas. ${ }^{20}$

Esses três modos de se comportar - expostos nos excertos coricianos recolhidos acima -, quais sejam: 1) vigiar os bens incessantemente para que nenhuma quantia seja perdida, 2) não ser dado a luxos, como banquetes, festivais, jogos etc., e 3) recalcular o valor das propriedades/gastos visando a uma maior economia, são lugares-comuns da personagem velho avarento nas declamações. Tais loci são encontrados também nas comédias novas e encontram respaldo nas teorizações sobre o

\footnotetext{
${ }^{18}$ Corício, Decl. $6 \$ 5$.

${ }^{19}$ Corício, Decl. $6 \$ 7$.

${ }^{20}$ Corício, Decl. $6 \$ 9$.
} 
avarento encontradas nos Caracteres de Teofrasto (especialmente, Char. X e XXX). Os exemplos a seguir são esclarecedores:

$\Sigma$ MIKPINH $\Sigma$

$[\pi i ́ v \varepsilon 1 \delta \dot{\varepsilon} \pi \circ \lambda v \tau \varepsilon \lambda \varepsilon \dot{\sigma} \sigma \alpha \tau o v$

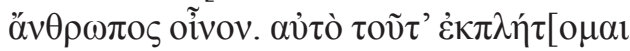

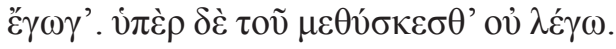

Esmícrines:

O homem bebe do

vinho mais caro. Isso me deixa chocado.

Quanto à bebedeira, não me importo. ${ }^{21}$

$\Sigma$ MIKPINH $\Sigma$

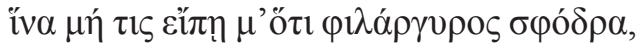

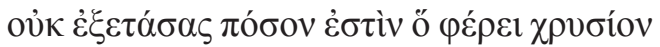

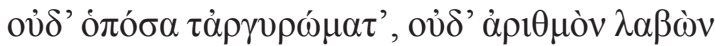

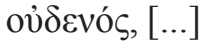

Esmícrines:

Para que ninguém fale que sou muito mesquinho, não contei quanto ouro ele carrega $\mathrm{e}$ nem quanta prata e não fiz conta alguma; $[\ldots]^{22}$

DEM O Iuppiter!

Hancin uitam! hoscin mores! hanc dementiam!

uxor sine dote ueniet, intus psaltriast.

domus sumptuosa, adulescens luxu perditus, senex delirans. [...]

Demeas: Ó Júpiter!

Que vida! Que comportamento! Que loucura!

Uma mulher sem dote virá, dentro há uma harpista.

A casa é majestosa, o jovem está estragado pelo luxo, o velho delira. $[\ldots]^{23}$

${ }^{21}$ Menandro, Epitrépontes, v. 126-128.

${ }_{22}$ Menandro, Aspis, v. 149-152.

${ }^{23}$ Terêncio, Adelphoí, v. 758-762. 
Os exemplos supramencionados evidenciam aspectos do caráter de três personagens cômicas e mostram que há uma conexão entre esses lugares-comuns cômicos e a forma segundo a qual Libânio e Corício apresentam seus avaros; os tópicos em comum se relacionam à aversão ao luxo, como deixa claro Esmícrines (Epit. 126-128), ao se chocar com o preço do vinho que o genro costumava beber, e Demeas em Adelphoí (v. 758-762), que considera ser uma loucura aceitar uma noiva sem dote. Em Lib. Decl. 31 (§13), por exemplo, o sovina afirma que prefere adotar uma dieta que "apenas os impede de morrer" ao invés de se banquetear.

Outro traço de caráter de velho mesquinho recorrente na declamação e nas comédias é o costume de fazer somas e subtrações, sempre calculando e recalculando quanto seria o gasto ou o lucro. Em Áspis (v. 149-152, trecho citado acima), Esmícrines diz que, para que não

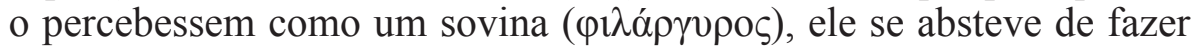

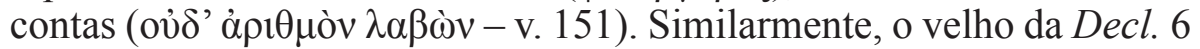
de Corício (trecho citado acima) explicita seu costume de fazer contas ( $\dot{\alpha} \rho 1 \theta \mu o ̀ v ~ \varepsilon ̇ \pi o เ o u ́ \mu \eta v-\S 9)$. Uma passagem declamatória na qual essa característica é bastante ressaltada pode ser vista em Lib. Decl. 32 (§9):

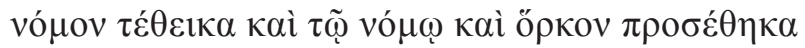

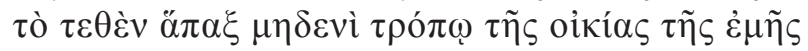
$\pi \rho \circ \varepsilon \xi \varepsilon \lambda \theta \varepsilon \tilde{\imath} v, \dot{\alpha} \lambda \lambda \dot{\alpha} \kappa \ddot{\alpha} v \lambda \imath \mu \tilde{\omega} \delta \varepsilon \dot{\varepsilon} \eta \varepsilon \theta v \alpha \dot{\alpha} v \alpha 1, \tau o \tilde{v}$

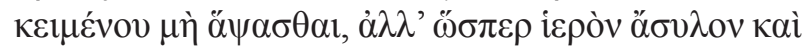

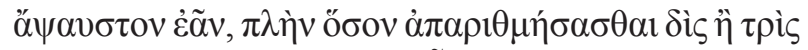

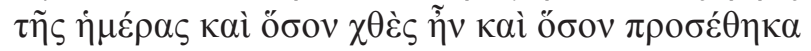

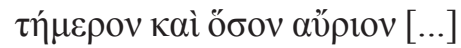

Eu estabeleci uma lei e, pela lei, jurei que jamais, de modo algum, uma aquisição sairia de minha casa; mesmo que fosse necessário morrer de fome, os bens não seriam tocados, mas sim mantidos inviolados, como sagrados, e não tocados, exceto quando duas ou três vezes ao dia eles fossem contados: quantos eram ontem, quantos são hoje, quantos serão amanhã. ${ }^{24}$

Demeas, na peça Adelphoí, de Terêncio, espanta-se com o fato de seu irmão, Mício, consentir em casar o filho com uma jovem sem

${ }^{24}$ Libânio, Decl. 32 §9. 
dote e, em v. 758-762 (passagem citada anteriormente), exclama o quanto julga ser uma demência aceitar a jovem sem dote. Esses são, precisamente, os mesmos julgamentos que faz o velho da Decl. 6 de Corício ao ponderar sobre o casamento de seu filho com a moça pobre. Destaco, especialmente, a relação que ambas as personagens propõem

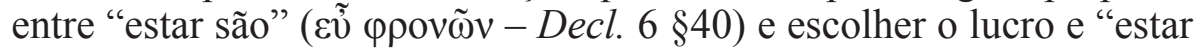
louco" (hanc dementiam! - Adelphoí, v. 759) e não o escolher:

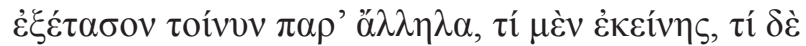

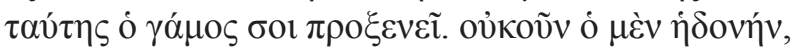

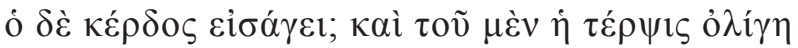
$\sigma v \mu \pi \alpha v o \mu \varepsilon \dot{\varepsilon} v \eta \tau \tilde{\omega} \pi$ ó$\theta \omega, \tau o \tilde{v} \delta \dot{\varepsilon} \tau o ̀ ~ \tau \tilde{\eta} \varsigma ~ \omega ̉ \varphi \varepsilon \lambda \varepsilon i ́ \alpha \varsigma$

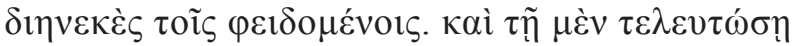

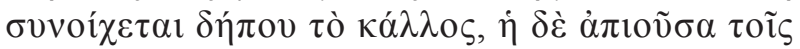

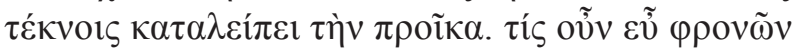

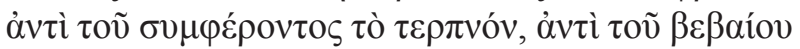
$\tau$ ò $\sigma \varphi \alpha \lambda \varepsilon \rho o ́ v, \dot{\alpha} v \tau i ̀ ~ \tau \tilde{\eta} \varsigma \dot{\varepsilon} \alpha v \tau o \tilde{v} \kappa \alpha \grave{\imath} \tau \tilde{\omega} v \pi \alpha i ́ \delta \omega v$

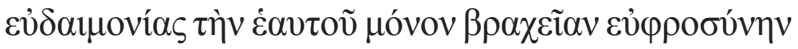

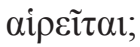

Compara qual casamento te traz mais benefícios, com aquela ou com essa. Um traz prazer, o outro o lucro. A parca felicidade do primeiro acaba quando o desejo acaba, já no outro, as vantagens são ininterruptas aos parcimoniosos. A beleza a acompanha na morte, a outra, ao partir, deixa aos filhos o dote. Quem, em sã consciência, preferiria o prazer ao lucro, o perigoso ao seguro, uma breve felicidade própria ao seu próprio bem-estar e ao dos filhos? ${ }^{25}$

Um outro dado importante é a similaridade entre o modo cauteloso e precavido dos sovinas das declamações (na Decl. 6 de Corício, o velho chega a se casar para compartilhar a vigília dos bens; na Decl. $32 \S 9$ de Libânio, o sovina diz que não comenta com servos, amigos ou parentes que tem dinheiro, temendo que alguém o roube ou peça um empréstimo) e nas comédias, especialmente a personagem Euclião na Aululária. Em Decl. $6 \S 3-5$, o velho conta que herdara uma

${ }^{25}$ Corício, Decl. $6 \S 41$ (grifo meu). 
modesta fortuna de seu pai. Tendo em vista o cuidado com esse dinheiro,

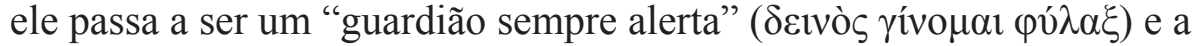
desconfiar de qualquer barulho que seja, além de observar com cautela os criados. Esse traço da personalidade do velho lembra o ressabiado Euclião, que, ao encontrar um pote repleto de ouro em sua casa, torna-se paranoico. Ressalto o fato de ambos os velhos não conseguirem dormir durante a noite, temendo ladrões. Compare-se Decl. 6 \$5 (trecho citado anteriormente) com o seguinte trecho plautino:

STA

Nescio pol quae illunc hominem intemperiae tenent:

Peruigilat noctes totas, tum autem interdius

Quasi claudus sutor domi sedet totos dies.

Estáfila:

Não sei quais inquietações assolam este homem.

Ele vigia durante toda a noite. Em seguida, ele

fica em casa o dia todo sentado como um sapateiro coxo. ${ }^{26}$

Destaco também o fato de ambos os velhos (o de Chor. Decl. 6 e Euclião) vigiarem suas posses e temerem qualquer barulho. Euclião, por exemplo, em diálogo com Megadoro, ouve um tilintar (quid crepuit quasi ferrum modo? - v. 242) próximo de sua casa e teme por seu tesouro; o barulho, porém, era proveniente dos jardineiros que trabalham no quintal de Megadoro. Antes que Megadoro pudesse explicar a origem do tilintar, Euclião já havia saído de cena para conferir se seu tesouro se encontrava seguro. Além do receio quanto aos barulhos estranhos

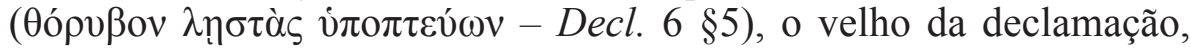

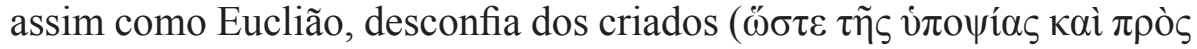

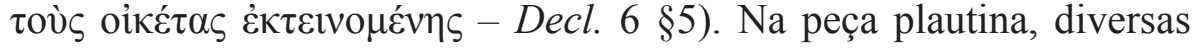
são as passagens nas quais Euclião ameaça os criados: logo no início do primeiro ato, Euclião aparece açoitando Estáfila (v. 40-67). Depois, novamente, em v. 268 et seq., o velho briga com a escrava, e, em v. 630 et seq., o velho enxota o escravo de Licônides.

Por fim, ainda nesse tópico do cuidado exagerado com as posses, chamo atenção para uma passagem da Decl. 32 de Libânio que torna clara a filiação entre declamação e comédia nova. Trata-se de uma apóstrofe

${ }^{26}$ Plauto, Aulularia, v. 71-73 (grifo meu). 
lançada pelo sovina ao seu próprio dinheiro, algo já visto, por exemplo, na Aululária, na qual Euclião se direciona ao seu pote de ouro:

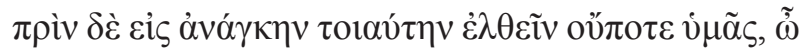

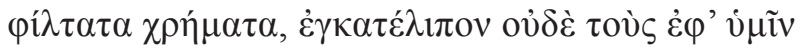

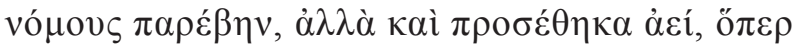

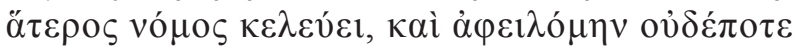

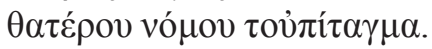

Meu querido dinheiro, antes dessa necessidade chegar, eu jamais te abandonei nem transgredi as leis que zelam por ti. Ao contrário, eu sempre adicionei mais, o que a primeira lei demanda, e nunca subtraí, que é uma condição da outra lei. ${ }^{27}$

EVCL.

Edepol, ne tu, aula, multos inimicos habes

atque istuc aurum quod tibi concreditum est. nunc hoc mihi factu est optumum, ut ted auferam, aula, in Fidei fanum: ibi abstrudam probe.

Euclião:

Por Pólux! Tu, pote, tens muitos inimigos;

Tu e o ouro que foi confiado a ti.

Agora o melhor que eu posso fazer é te levar, pote, para o templo da Boa Fé: lá te esconderei bem. ${ }^{28}$

Essa breve exposição, portanto, mostra que há semelhanças entre a caracterização dos avarentos das declamações gregas e os das comédias novas, na medida em que os mesmos traços éticos estão presentes nos dois gêneros citados. Tal fato denota que os declamadores tinham conhecimento aprofundado das comédias de Menandro, como evidenciado pelos testemunhos antigos, e que brincavam com alusões a esses textos em suas declamações. Mas por quê?

Primeiramente, a declamação era um exercício escolar e, por isso, estava fundamentada no universo de rapazes de não mais de dezoito anos, ainda que saibamos que declamações eram proferidas por e para homens

\footnotetext{
${ }^{27}$ Libânio, Decl. 32 §13.

${ }^{28}$ Plauto, Aulularia, v. 580-583.
} 
adultos em contexto extraescolar. Desse modo, os temas declamatórios seriam atrativos a esses jovens em idade escolar. Sobre isso, o ínicio do Satíricon (III), de Petrônio, é elucidativo; Agamêmnon estabelece uma analogia entre o "professor de retórica" (eloquentiae magister), e um pescador, ao dizer que ambos devem trabalhar com as iscas preferidas de seus alvos, caso contrário "ficariam sozinhos na escola" (soli in scholis relinquetur).

As comédias de Menandro foram lidas e estudadas nos círculos de estudo da oratória justamente por serem consideradas, ao mesmo tempo, uma fonte de sabedoria, de onde eram extraídas máximas morais, e um divertimento. Elas eram capazes de instruir: com relação a questões sociais (as máximas incutiam determinados pensamentos e costumes na mente dos rapazes); ${ }^{29}$ como material de alfabetização (o grego simples de Menandro oferecia uma menor dificuldade); a partir do ponto de vista discursivo-argumentativo (os embates entre personagens eram considerados bons exemplos de retórica forense); ${ }^{30}$ e, sobretudo, com relação à construção do caráter das personagens, que, como pessoas retiradas do cotidiano (lembre-se da indagação do gramático Aristófanes: “Menandro e Vida, quem de vós imitou quem?"), eram adequadas ao tipo de exercício que preparava o jovem ao tribunal. Elas também eram capazes de distrair: sabe-se que os dramas menandrianos, no período imperial, eram representados em simpósios e teatros, por exemplo, como forma de diversão. Espirituosos e leves, mas recheados de alusões literárias e quiproquós, os enredos de Menandro não deixavam de oferecer

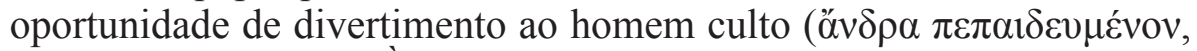
como fala Plutarco). ${ }^{31}$ À vista disso, a presença de personagens cômicas em exercícios de retórica se explica.

\footnotetext{
${ }^{29}$ Sobre essa questão, Cf. Gruber (2008).

${ }^{30}$ Quintiliano, 10.1.70.

${ }^{31}$ Cf. Plutarco, Comparação entre Aristófanes e Menandro (Moralia, $854 \sim$ Men. T 41 $\mathrm{K}-\mathrm{T}$ ).
} 


\section{Referências}

ANDERSON, G. Rhetoric and the Second Sophistic. In: DOMINIK, W.; HALL, J. A Companion to Roman rhetoric. Oxford: Blackwell, 2007. p. 339-353.

BERRY, D.; HEATH, M. Oratory and declamation. In: PORTER, S. (Org.). Handbook of Classical rhetoric. Leiden: Brill, 1997. p. 393-420.

BLOOMER, M. Schooling in persona: imagination and subordination in Roman education. Classical Antiquity, Berkeley, v. 16, p. 57-78, 1997.

BONNER, S. Roman declamation in the Late Republic and Early Empire. Liverpool: University Press of Liverpool, 1949.

BOWERSOCK, G. Greek Sophists in the Roman Empire. Oxford: Clarendon Press, 1969.

BOWIE, E. Greeks and their past in the Second Sophistic. Past \& Present, Oxford, n. 46, p. 3-41, 1970.

BREIJ, B. Pseudo-Quintilian's "Major Declamations": beyond school and literature. Rhetorica, Berkeley, v. 27, p. 354-369, 2009.

BROWN, P. G. McC. Masks, names and characters in New Comedy. Hermes, Stuttgart, v. 115, p. 181-202, 1987.

CALBOLI, G. L'eros nelle declamazioni latine (una pozione di controamore). Rhetorica, Berkeley, v. 28, p. 138-59, 2010.

CORBEILL, A. Rhetorical education and social reproduction in the Republic and early Empire. In: DOMINIK, W.; HALL, J. A Companion to Roman rhetoric. Oxford: Blackwell, 2007. p. 68-82.

CORBEILL, A. A Student speaks for social equality in the Roman classroom (Quintilian, "Declamationes Minores" 260). In: DINTER, M. et alii (Org.). Reading Roman declamation: the "Declamations" ascribed to Quintlian. Berlin: De Gruyter, 2015. p. 17-25.

CORCELlA, A. Choriciana. Paideia, Brescia, v. 60, p. 79-93, 2005.

CRIBIORE, R. Gymnastics of the mind: Greek education in Hellenistic and Roman Egypt. New Jersey: Princeton University Press, 2001.

CRIBIORE, R. The value of a good education: Libanius and public authority. In: ROUSSEAU, P. (Org.). A Companion to late Antiquity. Oxford: Wiley-Blackwell, 2009. p. 233-245. 
CRIBIORE, R. Libanius the sophist: rhetoric, reality and religion in the fourth century. New York: Cornell University Press, 2013.

DESBORDES, F. La rhétorique antique. Paris: Hachette Livre, 1996.

DINTER, M. et alli (Org.). Reading Roman declamation: the declamations ascribed to Quintilian. Berlin: De Gruyter, 2015.

FANTHAM, E. Roman experience of Menander in the late Republic and early Empire. Transactions and proceedings of the American Philological Association, Baltimore, v. 114, p. 299-309, 1984.

FANTHAM, E. Disowning and dysfunction in the declamatory family. Materiali e discussioni per l'analisi dei testi classici, Pisa, v. 53, p. 65-82, 2004.

GOLDHILL, S. Rhetoric and the Second Sophistic. In: GUNDERSON, E. (Org.). The Cambridge Companion to ancient rhetoric. Cambridge: Cambridge University Press, 2009. p. 228-244.

GUNDERSON, E. (Org.). The Cambridge Companion to ancient rhetoric. Cambridge: Cambridge University Press, 2009.

HÖMKE, N. "Not to win, but to please": Roman declamation beyond education. In: MONTEFUSCO, L. (Org.). Papers on rhetoric VIII: declamation, proceedings at the seminars held at the Scuola Superiore di Studi Umanistici (Bologna, February-March 2006). Roma: Herder Editrice, 2007. p. 103-128.

HÖMKE, N. The declaimer's one-man show: playing with roles and rules in the Ps.-Quintilian "Declamationes Maiores". Rhetorica, Berkeley, v. 27, n. 3, p. 240-255, 2009.

HUNTER, R. The New Comedy of Greece and Rome. Cambridge: Cambridge University Press, 1985.

JOHANSSON, M. Libanius' Declamations 9 and 10. Stockholm: Acta Universitatis Gothoburgensis, 2006.

KASTER, R. Notes on "primary" and "secondary" schools in late Antiquity. Transactions and proceedings of the American Philological Association, Baltimore, v. 113, p. 323-346, 1983.

KASTER, R. Controlling reason: declamation in rhetorical education at Rome. In: TOO, Y. L. (Org.). Education in Greek and Roman Antiquity. Brill: Leiden, 2001, p. 317-337. 
KENNEDY, G. The art of persuasion in Greece. London: Routledge \& Kegan Paul, 1963.

KENNEDY, G. The sophists as declaimers. In: BOWERSOCK, G. (Org.). Approaches to the Second Sophistic. Pennsylvania: University Park, 1974. p. 17-22.

KENNEDY, G. Greek rhetoric under Christian emperors. Princeton, N.J: Princeton University Press, 1983.

KENNEDY, G. Classical rhetoric and its Christian \& secular tradition from ancient to modern times. Chapel Hill: University of North Carolina Press, 1999.

KENNEDY, G. Progymnasmata: Greek textbooks of prose composition and rhetoric introduction and translation. Atlanta: Society of Biblical Literature, 2003.

LITSAS, F. Choricius of Gaza, an approach to his work: introduction, translation, commentary. 1980. 327 f. Tese (Doutorado) - Faculdade de Ciências Sociais da Universidade de Chicago, 1980.

LUPI, S. Coricio di Gaza, XVII (=decl. 4) F.-R.: Milziade. Introduzione, traduzione e commento. Berlin: Rombach Verlag, 2010.

LUPI, S. Two laws, two loves: generational conflict between a father and his son in Choricius" "Declamations" 5 and 6. In: AMATO, E. et alli (Org.). Law and ethics in Greek and Roman declamation. Berlin: De Gruyter, 2015. p. 303-332.

MACCARY, T. Menander's characters: their names, roles and masks. Transactions and proceedings of the American Philological Association, Baltimore, v. 101, p. 277-290, 1970.

MACCARY, T. Menander's old men. Transactions and proceedings of the American Philological Association, Baltimore, v. 102, p. 303-325, 1971.

MORGAN, T. Literate education in the Hellenistic and Roman worlds. Cambridge: Cambridge University Press, 1998.

MORGAN, T. Rhetoric and education. In: WORTHINGTON, I. (Org.). A companion to Greek rhetoric. Oxford: Wiley-Blackwell, 1970. p. 303-319. 
PACK, R. A. On the plot of Menander's "Dyscolus". Classical Philology, Chicago, v. 30, n. 2, 19, p. 151-160, 1935.

PENELLA, R. (Org.). Rhetorical exercises from late Antiquity: a translation of Choricius of Gaza's preliminary talks and declamations. Cambridge: Cambridge University Press, 2009.

RUSSELL, D. Greek declamation. Cambridge: Cambridge University Press, 1983.

RUSSEL, D. Libanius imaginary speeches: a selection of declamations translated with notes. London: Duckworth, 1996.

SCHOULER, B. Choricius déclamateur. In: SALIOU, C. (Org.). Gaza dans l'Antiquité tardive: archéologie, rhétorique, histoire. Salerno: Helios, 2005. p. 117-133.

STRAMAGLIA, A. The hidden teacher: "metarhetoric" in Ps.-Quintilian's "Major Declamations". In: DINTER, M. et alli (Org.). Reading Roman declamation: the declamations ascribed to Quintilian. Berlin: De Gruyter, 2015. p. 27-51.

SUSSMAN, L. Sons and fathers in the "Major Declamations" ascribed to Quintilian. Rhetorica, Berkeley, v. 13, p. 179-192, 1995.

VAN MAL-MAEDER, D. La fiction des déclamations. Leiden: Brill, 2007.

WEBB, R. Rhetorical and theatrical fictions in Chorikios of Gaza. In: JOHNSON, S. F. (Org). Greek literature of late Antiquity: dinamism, didactism and classicism. Farnham: Ashgate, 2006. p. 107-124.

WINTERBOTTOM, M. Roman declamation. Bristol: Bristol Classical Press, 1980.

WINTERBOTTOM, M. Scholroom and courtroom. In: VICKERS, B. (Org.). Rhetoric revalued. New York: Center for Medieval and early Renaissance Studies, 1982. p. 59-69.

WORTHINGTON, I. (Org.). A companion to Greek rhetoric. Oxford: Wiley-Blackwell, 2010. 